\title{
Mechanical and surface properties analysis of restorative materials submitted to erosive challenges in situ
}

\author{
Ana Paula Albuquerque Guedes ${ }^{1}$, Bruna Oliveira-Reis ${ }^{1}$, Anderson Catelan ${ }^{2}$, \\ Thaís Yumi Umeda Suzuki ${ }^{3}$, André Luíz Fraga Briso ${ }^{1}$, Paulo Henrique Dos Santos ${ }^{4}$
}

Correspondence: Dr. Paulo Henrique Dos Santos

Email: paulosantos@foa.unesp.br

\begin{abstract}
'Department of Restorative Dentistry, Araçatuba School of Dentistry, UNESP - São Paulo State University, Araçatuba, São Paulo, Brazil, ${ }^{2}$ Department of Restorative Dentistry, Piracicaba School of Dentistry, Campinas State University, Piracicaba, Brazil,

${ }^{3}$ Department of Restorative Dentistry, Federal University of Minas Gerais, Minas Gerais, Brazil, ${ }^{4}$ Department of Dental Materials and Prosthodontics, Araçatuba School of Dentistry, UNESP - São Paulo State University, Araçatuba, São Paulo, Brazil
\end{abstract}

\section{ABSTRACT}

Objective: This study aims to evaluate the effect of acidic solutions (AS) on surface roughness (Ra) and microhardness of restorative materials (RM). Materials and Methods: Eight volunteers wore intraoral palatal devices (IPD) containing samples of RM: Ketac Nano (KN); Ketac Nano + Biscover LV (KN-B); Esthet-X (EX); Esthet-X + Biscover LV (EX-B); Supreme XT (SXT); Supreme XT + Biscover LV (SXT-B); and bovine enamel. The samples were submitted to three phases: (1) immersion in $0.01 \mathrm{M}$ hydrochloric acid $(\mathrm{HCl})-10 \mathrm{~min}$, three times/day (14 days); (2) immersion in soft drink (Sprite $\left.{ }^{\circledR}\right)$ - $10 \mathrm{~min}$, three times/day (14 days); and (3) keeping in saliva (14 days). Changes in $\mathrm{Ra} /$ microhardness were measured before/after the three phases. Statistical Analysis: ANOVA $(\alpha=0.05)$ and Fisher's test. Results: Materials sealed with Biscover LV (B) presented lowest values in all periods. KN glass ionomer cement showed highest Ra values after exposure in AS. Application of B did not reduce the Ra for the composites studied, except for EX after immersion in $\mathrm{HCl}$. AS promoted changes in $\mathrm{Ra} /$ microhardness of RM, except for sealed materials. Conclusions: The acids used were able to change the Ra and microhardness of RM, except of the sealed materials. The resin-modified GIC showed the most significant changes after immersion in AS; and the composites sealed with B, even after immersion in acidic solutions (AS), showed the lowest Ra values and the least degradation in microhardness, especially when subjected to low $\mathrm{pH}$ solutions.

Key words: Carbonated drink, dental erosion, gastric juice, microhardness

\section{INTRODUCTION}

Dental erosion is a new risk for oral health, introduced by today's lifestyles and dietary habits.

\begin{tabular}{|l|l|}
\hline \multicolumn{2}{|c|}{ Access this article online } \\
\hline Quick Response Code: \\
\hline
\end{tabular}

This is an open access journal, and articles are distributed under the terms of the Creative Commons Attribution-NonCommercial-ShareAlike 4.0 License, which allows others to remix, tweak, and build upon the work non-commercially, as long as appropriate credit is given and the new creations are licensed under the identical terms.

For reprints contact: reprints@medknow.com

How to cite this article: Albuquerque Guedes AP, Oliveira-Reis B, Catelan A, Umeda Suzuki TY, Fraga Briso AL, Dos Santos PH. Mechanical and surface properties analysis of restorative materials submitted to erosive challenges in situ. Eur J Dent 2018;12:559-65.

DOI: 10.4103/ejd.ejd_188_18 
Erosion is a tooth wear attributed to dissolution of the dental-hard tissues by acids, without the involvement of bacteria and may be classified as extrinsic or intrinsic. ${ }^{[1]}$ Extrinsic factors include frequent consumption of acidic foodstuffs or beverages and some medications, ${ }^{[2]}$ while intrinsic factors are related to eating disorders and gastric reflux. ${ }^{[3]}$

Once in contact with enamel, the acid with hydrogen ion or its chelating capacity begins to dissolve the hydroxyapatite crystal. The nonionized form spreads throughout the enamel's interprismatic areas, dissolving the mineral in the subsurface region. ${ }^{[4]}$ Frequent contact between acids and tooth surfaces causes loss of this structure resulting in a surface susceptible to mechanical abrasion. ${ }^{[5]}$ Furthermore, in severe situations, as in gastroesophageal reflux disease (GERD), a significant loss of tooth structure, vertical dimension, and/ or function, hypersensitivity, esthetically unacceptable defects, and pulp exposure could occur. ${ }^{[1]}$

In the past, patients were left untreated or the rehabilitation was performed with extensive crown and bridge work. ${ }^{[6,7]}$ However, as a result of the improvements in adhesive materials, it has become possible to rehabilitate eroded teeth in a less invasive manner using direct restorative material (RM) such as composite resins and glass ionomer cement (GIC). ${ }^{[6,7]}$ These materials are capable of reestablishing the function and esthetics of tooth structure as well as controlling the hypersensitivity. ${ }^{[1]}$

It is known that the longevity of dental restorations depend on the durability of the material and its properties such as wear resistance, integrity of the tooth/restoration interface, surface roughness (Ra), and microhardness. ${ }^{[7]}$ To preserve or improve the properties of direct RM, surface sealants were developed. According to the literature, ${ }^{[8,9]}$ this is a dental biomaterial where nanotechnology was applied that is able to improve the properties of existing materials, by filling the cracks, decreasing the porosity, increasing the wear resistance, and maintaining the marginal integrity of restorations.

This study aimed to evaluate in situ the effect of different acidic solution (AS) on Ra and microhardness of RM, including a sealed composite. The null hypothesis was that AS cause any effect on the Ra and microhardness of RM.

\section{MATERIALS AND METHODS}

\section{Screening of participants}

After receiving all relevant information to conduct the research, the volunteers underwent an anamnesis and clinical examination for the inclusion and exclusion criteria checking. The inclusion criteria applied for selection of research volunteers were good general health, normal salivary flow, absence of active caries lesions, no noncarious injuries (e.g., cervical lesions), absence of periodontal disease, absence of prosthesis, absence of orthodontic appliances, and availability to attend the research site. Furthermore, the exclusion criteria were as follows: medical treatment, digestive disorder, use of any drug, pregnancy, and smoking habit. Eight volunteers (four men and four women) with a mean age of 22 years were selected for this research.

Specimen preparation, microhardness, and profilometric measurements

A total of 48 samples of each material (Ketac Nano $[\mathrm{KN}]$, Esthet-X [EX] and Supreme XT [SXT]) measuring $4 \mathrm{~mm}$ in diameter and $1.5 \mathrm{~mm}$ in thickness were made, using a metal die. The die cavity was completely filled with the materials. A polyester strip and a thin glass plate were placed on the material surface to remove the excess and standardize the finishing of the samples. The materials were light polymerized for 40s (Ultralux, Dabi Atlante, Ribeirão Preto, SP, and Brazil) and then stored in distilled water at $37^{\circ} \mathrm{C}$ for $24 \mathrm{~h}$. After that, the sample's surfaces were ground flat with water-cooled carborundum discs (\# 600, 800, and 1200 Grades of $\mathrm{Al}_{2} \mathrm{O}_{3}$ papers; Extec, Corp., Enfield, CT, USA) and polished with felt paper wet by diamond spray $(1 \mu \mathrm{m}$; Extec). The samples were cleaned in an ultrasonic cleaning device (Cristófoli, Campo Mourão, $\mathrm{SP}$, Brazil) for $10 \mathrm{~min}$ after each disc and after the final polishing.

Half of the samples were etched with $32 \%$ phosphoric acid (Bisco Inc., Schaumburg, IL, USA) for $15 \mathrm{~s}$, washed with distilled water, and dried with air spray. On the conditioned surfaces, the surface sealant B was applied (Bisco Inc., Schaumburg, IL, USA) and light polymerized for $30 \mathrm{~s}$.

Twenty-four enamel samples $(4 \mathrm{~mm} \times 4 \mathrm{~mm} \times 1.5 \mathrm{~mm})$ were prepared from extracted bovine incisors, which were previously stored in $2 \%$ formaldehyde solution ( $\mathrm{pH} 7.0$ ) for 30 days at room temperature. One sample was cut from each crown, using an APL-4 cutting machine (Arotec Ind. Com., Cotia, SP, 
Brazil). The enamel surface was also ground flat with water-cooled carborundum discs (\# 320, 600, 800, and 1200 Grades of $\mathrm{Al}_{2} \mathrm{O}_{3}$ papers; Extec) and polished with felt paper wet by diamond spray $(1 \mu \mathrm{m}$; Extec $)$. The enamel samples were also cleaned in an ultrasonic cleaning device (Cristófoli) for $10 \mathrm{~min}$ after each disc and after the final polishing. Bovine enamel was used as an intrinsic control of each group to confirm that the erosive period adopted in this research could lead to the erosion of the specimens.

The surface microhardness was determined by performing five indentations in different regions of the samples (Knoop diamond, 25g, 10 s, HMV-2000; Shimadzu Corporation, Tokyo, Japan). The Ra was determined using a profilometer (SJ-401, Mitutoyo, Kanagawa, Japan). The Ra value was used because it represents the arithmetical mean of roughness of a surface, and it is the most used parameter for this purpose. Each measurement was obtained after turning the specimen $120^{\circ}$, totaling three measurements using a cutoff of $0.25 \mathrm{~mm}$.

Intraoral phase: mouth appliances, tested products, and intervention.

Alginate impressions (hydrogun) were made directly from eight volunteers producing a negative mold, in which dental stone was poured. The intraoral palatal devices (IPD) were manufactured with acrylic resin. Seven holes measuring $4 \mathrm{~mm} \times 4 \mathrm{~mm} \times 2 \mathrm{~mm}$ were prepared to fix the specimens. Each one received one sample of each material as well as one enamel sample. The samples were fixed with wax into cavities $(4 \mathrm{~mm} \times 4 \mathrm{~mm} \times 2 \mathrm{~mm})$ located at each left and right sides of the IPD. The position of each sample was defined by drawing. The experimental design of the crossover study is showed in Figure 1.

In the first phase of this study, volunteers were instructed to immerse the IPD in $30 \mathrm{~mL}$ of $\mathrm{HCl}$ at a concentration of $0.01 \mathrm{M}$ (Dinâmica ${ }^{\circledR}$, Química Contemporânea Ltda, Diadema, SP, Brazil), pH 2.0 for $10 \mathrm{~min}^{[7]}$ and three times a day during 14 days. The erosive solution was renewed for each erosive challenge. After the immersion, the intraoral devices were washed with water for $30 \mathrm{~s}$ and then replaced into the mouth. In the first $12 \mathrm{~h}$ of the intraoral phase, samples were not subjected to erosive treatment to allow the formation of a salivary pellicle. ${ }^{[5]}$ After this first phase, the samples were removed and new Ra and microhardness measurements were done in the same manner as described above.

In the second phase, new samples of each material were positioned in the same holes of the intraoral device

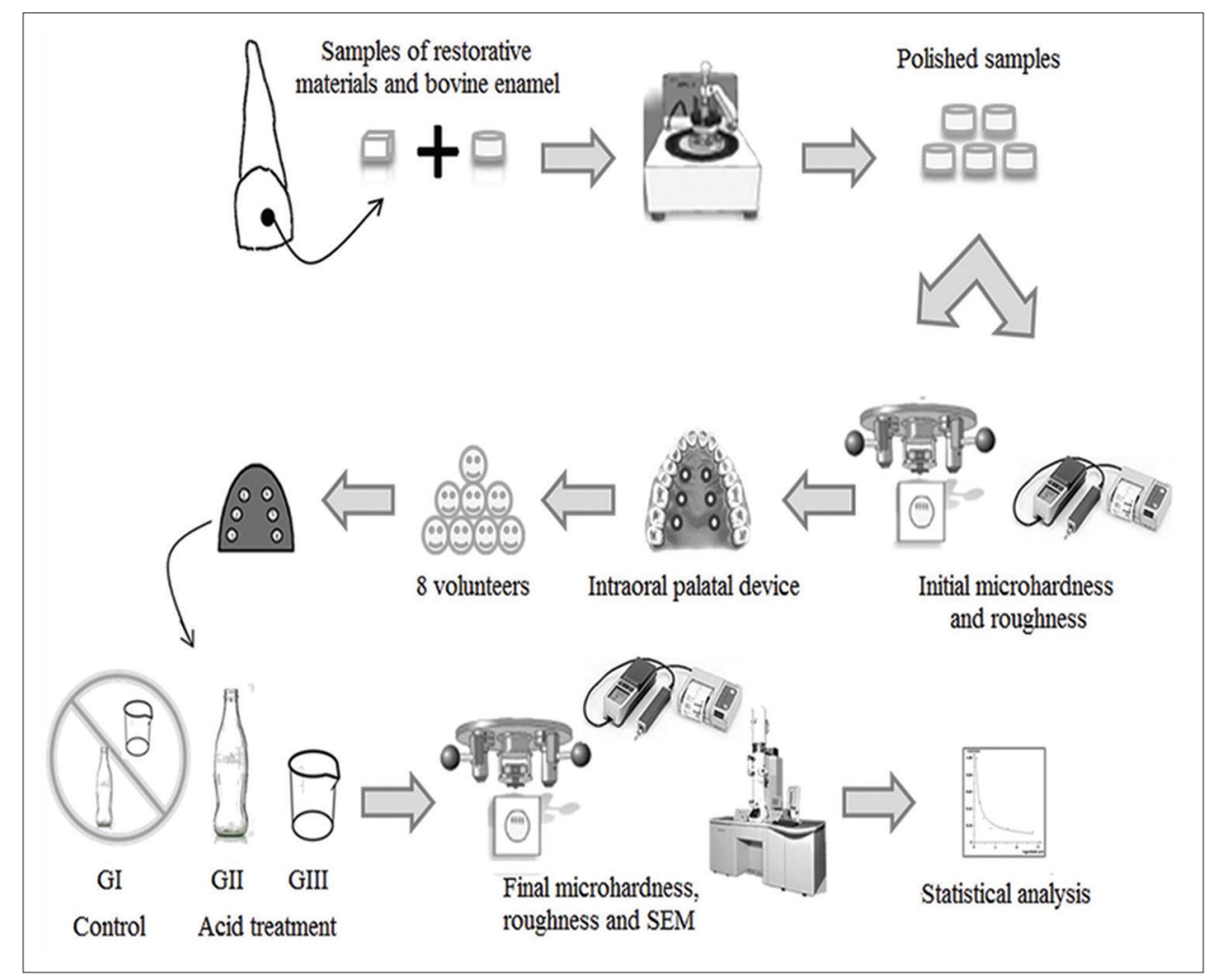

Figure 1: Experimental design used in the study 
and the same volunteers were instructed to immerse intraoral devices in $30 \mathrm{~mL}$ of soft drink (SD) (Sprite®, Coca-Cola Co, Ribeirão Preto, SP, Brazil), pH 3.6 for $10 \mathrm{~min}$ and three times a day during 14 days. Theerosive solution was renewed for each erosive challenge. After this second phase, the samples were removed and new $\mathrm{Ra}$ and microhardness measurements were done in the same manner as described above.

In the third phase, new samples of each material were positioned in the same holes of the intraoral device and the same volunteers were instructed to keep the samples only in saliva, without submitting them to any extraoral treatment during 14 days. The samples were removed and new Ra and microhardness measurements were done in the same manner as described above.

A washout period of 14 days was performed among the phases. Volunteers received instructions to wear the appliances continuously, but to remove them during meals. After meals, they had to brush their teeth using a soft toothbrush (Colgate Classic Clean, Colgate-Palmolive industrial LTDA, São Bernardo do Campo, SP, Brazil) with a small portion of the same fluoridated toothpaste (Colgate-Palmolive industrial LTDA, São Bernardo do Campo, SP, Brazil). During this period, the appliance was stored in wet gauze. After the brushing process was complete, the appliances were replaced into the mouth. Volunteers received oral and written information to refrain from using any fluoridated mouthwashes.

\begin{tabular}{|c|c|c|c|c|}
\hline & Baseline & Saliva & Sprite & $\mathrm{HCl}$ \\
\hline$\overline{\text { SXT }}$ & 82.7 (3.9) Aa & 81.5 (6.1) Aa & 76.2 (4.9) $\mathrm{Ba}$ & $60.7(13.6) \mathrm{Ca}$ \\
\hline SXT-B & 29.4 (1.6) Ad & 27.7 (2.9) ABe & 28.4 (3.2) Ade & $25.6(1.7) \mathrm{Bd}$ \\
\hline EX & 59.6 (3.3) Ab & 55.5 (2.9) Ab & 57.3 (7.6) Ab & 40.5 (9.7) Bb \\
\hline EX-B & 30.5 (2.7) Ad & 31.4 (2.3) Ad & 26.9 (2.8) Be & $25.4(2.0) \mathrm{Bd}$ \\
\hline $\mathrm{KN}$ & $45.2(3.1) A B c$ & 49.6 (2.7) Ac & 46.3 (9.6) Ac & $30.0(4.6) \mathrm{Cc}$ \\
\hline $\mathrm{KN}-\mathrm{B}$ & 32.1 (2.8) Ad & 33.7 (3.0) Ad & $31.2(3.4) \mathrm{Ad}$ & $26.8(3.4) \mathrm{Bd}$ \\
\hline
\end{tabular}

Postoral phase: microhardness, profilometric, and microscopic analysis.

After Ra and microhardness analysis, representative samples of each group were selected for microscopic examination using scanning electron microscope (SEM) (JSM-5410, JEOL, Tokyo, Japan).

\section{Statistical analysis}

The Ra and microhardness data were submitted to repeated-measures ANOVA at 5\% significance level and pairwise comparisons were performed using the Fisher's post-hoc test (software Statview 5.0.1).

\section{RESULTS}

Microhardness results are in Table 1 . The aging of the materials in $\mathrm{HCl}$ caused decrease in microhardness, with significant difference to other solutions and initial values. Storage in SD caused decrease in microhardness only to SXT and Esthet-X + Biscover LV (EX-B) with significant difference to initial values. For other materials, the SD did not cause significant changes in microhardness. There was no difference between microhardness values, before and after in situ test performed only in saliva, for all materials studied.

Comparing the materials, the SXT composite resin (CR) showed highest microhardness average in all periods, followed by EX CR and KN GIC, with significant difference between them. The materials sealed with Biscover LV (B) presented the lowest microhardness compared to materials without sealing, in all periods.

Roughness results are in Table 2. The aging of the materials in $\mathrm{HCl}$ caused increase in Ra compared to initial values for all materials studied, except for the sealed ones. In the sealed materials, the difference from baseline and after immersion in saliva, SD, and $\mathrm{HCl}$ was not statistically significant. The SD caused increase in the Ra of GIC without sealing. The saliva caused increase in Ra for the composites SXT and EX with significant difference to initial values.

\begin{tabular}{lcccc}
\multicolumn{5}{l}{ Table 2: Initial and final Ra values of the studied materials $(\boldsymbol{\mu m})$} \\
\hline \multicolumn{1}{l}{ Baseline } & Saliva & Sprite & $\mathrm{HCl}$ \\
\hline SXT & $0.024(0.005) \mathrm{Cc}$ & $0.028(0.003) \mathrm{Bc}$ & $0.027(0.005) \mathrm{Bb}$ & $0.035(0.005) \mathrm{Ac}$ \\
SXT-B & $0.037(0.012) \mathrm{Aab}$ & $0.043(0.003) \mathrm{Aab}$ & $0.040(0.016) \mathrm{Ab}$ & $0.041(0.014) \mathrm{Abc}$ \\
EX & $0.028(0.007) \mathrm{Bc}$ & $0.040(0.015) \mathrm{Aab}$ & $0.027(0.005) \mathrm{Bb}$ & $0.051(0.028) \mathrm{Ab}$ \\
EX-B & $0.033(0.013) \mathrm{Ab}$ & $0.043(0.003) \mathrm{Aab}$ & $0.036(0.010) \mathrm{Ab}$ & $0.032(0.010) \mathrm{Ac}$ \\
KN & $0.040(0.008) \mathrm{Ba}$ & $0.048(0.015) \mathrm{Ba}$ & $0.076(0.043) \mathrm{Aa}$ & $0.078(0.016) \mathrm{Aa}$ \\
KN-B & $0.036(0.008) \mathrm{Aab}$ & $0.033(0.007) \mathrm{Abc}$ & $0.038(0.008) \mathrm{Ab}$ & $0.031(0.007) \mathrm{Ac}$ \\
\hline
\end{tabular}

${ }^{*}$ Distinct capital letter in columns and lower case letter in rows are statistically different $(P<0.05)$ 
Comparing the materials, the KN GIC had the highest Ra after EC. For this material, sealing with B possibly caused minor changes in Ra after aging in saliva, SD, and $\mathrm{HCl}$. The application of the sealant did not reduce Ra values for the two composites studied, except for EX after challenge in $\mathrm{HCl}$.

\section{DISCUSSION}

The design and conduct of this study were based on the evidence that after repeated exposure of dental enamel to gastric contents or acidic foods and beverages, a dental erosion typically occurs. ${ }^{[8]}$ Concurrently, with this approach, it is assumed that this acidic exposure could also have effects on RM. Once direct RM as CR and GIC are constantly used to repair eroded tooth surfaces, it was pertinent to investigate the effects of acidity on these materials as well as new techniques to increase the restorations longevity. ${ }^{[7,10]}$ Data analysis revealed that the AS altered the Ra and microhardness of the materials [Tables 1 and 2], rejecting the null hypothesis of the study.

Several studies that evaluated the effect of acids on ename $\mathrm{l}^{[3,4,7,8,11,12]}$ and $\mathrm{RM}^{[12]}$ under in vitro methodologies. However, in situ studies simulate a more realistic condition to that found clinically since they are conducted, in part, in the oral environment and suffer the environmental interference, such as saliva, ${ }^{[13]}$ temperatures, microorganisms, and enzymes. In this study, the action of saliva may have contributed to these results since it helps in the neutralization of the acids used in this research. ${ }^{[5]}$

In this study, the SD was chosen because of its large consumption, high erosive potential, and buffering capacity. According to Larsen and Nyvad, ${ }^{[14]}$ the capability of an SD to erode dental enamel depends not only of the $\mathrm{pH}$ of the drink but also of its buffering effect, the ability of the drink to resist a change of $\mathrm{pH}$. The solution of $\mathrm{HCl}(0.01 \mathrm{M}, \mathrm{pH} 2.0)^{[7]}$ would simulate a severe condition with high risk for the formation and progression of erosive lesions. In addition, despite that pure acids have a $\mathrm{pH}$ between 0.9 and $1.5,^{[11]}$ the $\mathrm{pH}$ in the oral cavity after episodes of vomiting rarely or never is $<1.5$ because of the buffering effect in the esophagus and dilution with food and drinks. ${ }^{[1]}$ Thus, the use of $\mathrm{HCl}$ solution in this concentration simulates a more real condition, making the situation clinically relevant.

The evaluation methods used in this research are very useful to quantify the changes of enamel and RM subjected to erosive challenges. ${ }^{[15]}$ The profilometer was used to measure the Ra of materials since previous studies ${ }^{[16]}$ have established that the critical threshold for the Ra is $0.2 \mu \mathrm{m}$, above which could occur a simultaneous increase in plaque accumulation, thereby increasing the risk for both caries and periodontal inflammation. The evaluation of the surface microhardness is sensitive in determining the erosive lesions at early stages ${ }^{[15]}$ and is considered an important indicator of materials' mechanical properties. ${ }^{[17]}$

The results of this study showed a significant change in Ra and microhardness after immersion in AS of SD and $\mathrm{HCl}$ [Tables 1 and 2]. In this context, Badra et al. ${ }^{[12]}$ also reported a decrease in the microhardness of CR and glass ionomer resin modified when immersed in SDs that have low $\mathrm{pH}$. It is believed that a reduction in the surface microhardness of $\mathrm{CR}$ soaked in organic acids has been attributed to the softening of bisphenol A glycidyl methacrylate (bis-GMA)-based polymers, which could be caused by leaching of the diluent agents such as triethylene glycol dimethacrylate (TEGDMA). ${ }^{[5]}$ The softening of the resin matrix could promote displacement of the filler particles, contributing to the formation of a rough surface, ${ }^{[12]}$ as observed and illustrated [Figure $2 c$, f and i] in this study.

The $\mathrm{pH}$, the titratable acidity (the volume of alkali needed to neutralize an acid), and dissociation constant (the ease with which $\mathrm{H}+$ are released from an acid) are factors in the chemistry of acids. ${ }^{[18]}$ It is probable that the titratable acidity or the dissociation constant are more important than the $\mathrm{pH}$ in assessing the erosive potential of an acidic solution. ${ }^{[19]}$ In our study, the hydrochloric acidic solution $(\mathrm{HCl} 0.01 \mathrm{M}, \mathrm{pH} 2.0)$ caused the largest changes in Ra and microhardness of RM when compared with the SD (Sprite ${ }^{\circledR}$ ) as observed in Figure $2 b, e$, and $h$. Our results are consistent with studies of Bartlett et al. ${ }^{[18]}$ that compared the erosive potential of gastric juice and carbonated drinks, demonstrating the sovereignty of the first one. These findings are a reflection of low $\mathrm{pH}$ and acidity of $\mathrm{HCl}$ when compared to the SD and confirm the assumptions that the gastric juice has the potential to produce severe erosion patterns in patients with eating disorders and GERD. ${ }^{[4]}$

It is important to consider the role of saliva in neutralizing acids. It is known that during the intake of acidic drinks, the $\mathrm{pH}$ of the oral environment falls below the critical value, the rate of salivary flow increases and the drinks are so diluted by saliva. ${ }^{[5]}$ 


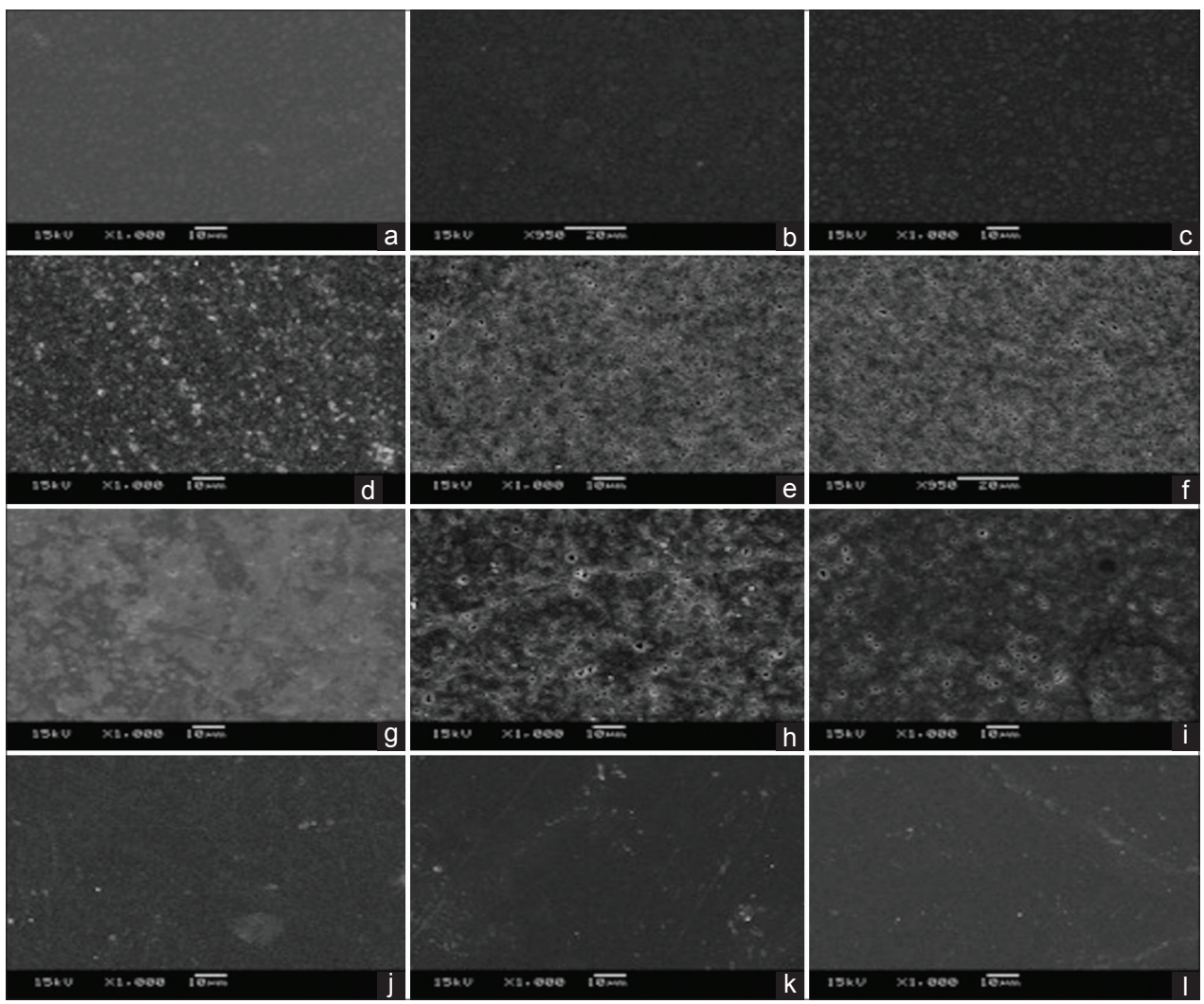

Figure 2: Microscopic images of samples (×1000). (a) Supreme XT after aging in saliva. (b) Supreme XT after aging in HCl. (c) Supreme XT after aging in soft drink (d) Esthet- $X$ after aging in saliva. (e) Esthet-X after aging in HCl. (f) Esthet-X after aging in soft drink. (g) Ketac Nano after aging in saliva. (h) Ketac Nano after aging in $\mathrm{HCl}$. (i) Ketac Nano after aging in soft drink. (j) Sealed materials after aging in saliva; (k) Sealed materials after aging in $\mathrm{HCl}$. (l) Sealed materials after aging in soft drink

This is because esophageal acid clearance occurs in a two-step procedure: peristalsis clearing the volume, followed by saliva neutralizing the acid. ${ }^{[13]}$ However, in this study, the interaction of saliva with the acidic solution may have been impaired because the samples were washed with water after the exposure to the solutions.

Comparing the materials, it was found that the $\mathrm{KN}$ glass ionomer was more unstable than the CR. These findings could be explained by matrix dissolution in the periphery of glass particles of glass ionomer, which could result from dissolution of the siliceous hydrogel layer [Figure $2 \mathrm{~h}$ and i]. ${ }^{[5,20]}$ Other factors that could also have contributed to these results are the manipulation and composition of these materials. The presence of glass particles in the composition of resin-modified glass ionomers, such as KN, may reduces its homogeneity and increases its surface roughness. Furthermore, the components have different microhardness, and they are manually handled, which can generate porosity because of the inclusion of visually imperceptible air bubbles [Figure 2g]. ${ }^{[21]}$ SEM studies of Abu-bakr et al. ${ }^{[22]}$ have shown images of rough surfaces with the presence of voids and protruding glass particles, which clinically add up to a rough and dull surface, which could explain the higher Ra values of resin-modified glass ionomer materials [Table 2].

On the other hand, under acidic conditions, the composites were more stable due to the formulation of the material and morphology of the filler particles, which are nanosized and regular, allowing the incorporation of a large inorganic volume. ${ }^{[23]}$ This statement explains the higher microhardness values found for the SXT. According to Dos Santos et al., ${ }^{[6]}$ composites with small filler particles are more wear-resistant since they are more homogeneous and their particles are less prominent on the surface, resulting in a lower roughness as showed in Figure 2a. Whereas the type of filler, size, and quantity of the particles influence the properties and quality of polishing of composite resins (for example Figure $2 \mathrm{~d}$ ), the reduction in space between the inorganic nanoclusters ${ }^{[23]}$ is possibly responsible for the superior physical properties of SXT.

In this study, the composite resin sealed with B showed significantly lower microhardness values when 
compared with the values of unsealed resins [Table 1]. These differences could be attributed to resin monomers and the ethanol solvent present in the sealant surface. Bertrand et al. ${ }^{[24]}$ demonstrated that when examined by SEM, the sealant was shown to reduce the surface microhardness, improving the surface quality of composites because of the disappearance of microcracks and minor surface irregularities. However, according to the results of the present study, the maintenance of lower $\mathrm{Ra}$ and microhardness values for the sealed composite after immersion in AS as well as the nonexposure of the particles as illustrated in microscopy images [Figure 2j, k, and l] could be indicative of the sealing material remaining on the composite surface, showing that the material was able to withstand the acidic challenges.

\section{CONCLUSIONS}

Data from this study demonstrated some of the changes caused by low $\mathrm{pH}$ solutions in direct $\mathrm{RM}$ concluding that: (1) The acids used in this study were able to change the Ra and microhardness of RM, except of the sealed materials; (2) The resin modified GIC showed the most significant changes after immersion in AS; and (3) The composites sealed with B, even after immersion in acidic solutions (AS), showed the lowest Ra values and the least degradation in microhardness, especially when subjected to low $\mathrm{pH}$ solutions. However, further research is needed to assess simultaneously the effect of other degradation processes such as mechanical abrasion. In addition, to complement the results of this research, a long time erosion could be used to assess differences in the behavior of RM as well as clinical and epidemiological studies.

\section{Financial support and sponsorship Nil.}

\section{Conflicts of interest}

There are no conflicts of interest.

\section{REFERENCES}

1. AlShahrani MT, Haralur SB, Alqarni M. Restorative rehabilitation of a patient with dental erosion. Case Rep Dent 2017;2017:9517486.

2. Watanabe M, Nakatani E, Yoshikawa H, Kanno T, Nariai Y, Yoshino A, et al. Oral soft tissue disorders are associated with gastroesophageal reflux disease: Retrospective study. BMC Gastroenterol 2017;17:92.

3. Oliveira GC, Tereza GP, Boteon AP, Ferrairo BM, Gonçalves PS, Silva TC, et al. Susceptibility of bovine dental enamel with initial erosion lesion to new erosive challenges. PLoS One 2017;12:e0182347.

4. Bartlett DW, Evans DF, Anggiansah A, Smith BG. A study of the association between gastro-oesophageal reflux and palatal dental erosion. Br Dent J 1996;181:125-31.

5. Rios D, Honório HM, Francisconi LF, Magalhães $A C$, de Andrade Moreira Machado MA, Buzalaf MA, et al. In situ effect of an erosive challenge on different restorative materials and on enamel adjacent to these materials. J Dent 2008;36:152-7.

6. dos Santos PH, Consani S, Correr Sobrinho L, Coelho Sinhoreti MA. Effect of surface penetrating sealant on roughness of posterior composite resins. Am J Dent 2003;16:197-201.

7. Hove LH, Holme B, Young A, Tveit AB. The protective effect of TiF4, SnF2 and NaF against erosion-like lesions in situ. Caries Res 2008;42:68-72.

8. de Carvalho Sales-Peres SH, Magalhães AC, de Andrade Moreira Machado MA, Buzalaf MA. Evaluation of the erosive potential of soft drinks. Eur J Dent 2007;1:10-3.

9. Khurshid Z, Zafar M, Qasim S, Shahab S, Naseem M, AbuReqaiba A, et al. Advances in nanotechnology for restorative dentistry. Materials (Basel) 2015;8:717-31.

10. Aliping-McKenzie M, Linden RW, Nicholson JW. The effect of coca-cola and fruit juices on the surface hardness of glass-ionomers and 'compomers'. J Oral Rehabil 2004;31:1046-52.

11. Hove L, Holme B, Øgaard B, Willumsen T, Tveit AB. The protective effect of TiF4, SnF2 and NaF on erosion of enamel by hydrochloric acid in vitro measured by white light interferometry. Caries Res 2006;40:440-3.

12. Badra VV, Faraoni JJ, Ramos RP, Palma-Dibb RG. Influence of different beverages on the microhardness and surface roughness of resin composites. Oper Dent 2005;30:213-9.

13. Moazzez R, Bartlett D, Anggiansah A. Dental erosion, gastro-oesophageal reflux disease and saliva: How are they related? J Dent 2004;32:489-94.

14. Larsen MJ, Nyvad B. Enamel erosion by some soft drinks and orange juices relative to their $\mathrm{pH}$, buffering effect and contents of calcium phosphate. Caries Res 1999;33:81-7.

15. Attin T. Methods for assessment of dental erosion. Monogr Oral Sci 2006;20:152-72.

16. Bollen CM, Lambrechts P, Quirynen M. Comparison of surface roughness of oral hard materials to the threshold surface roughness for bacterial plaque retention: A review of the literature. Dent Mater 1997;13:258-69.

17. Kakaboura A, Rahiotis C, Zinelis S, Al-Dhamadi YA, Silikas N, Watts DC, et al. In vitro characterization of two laboratory-processed resin composites. Dent Mater 2003;19:393-8.

18. Bartlett DW, Coward PY. Comparison of the erosive potential of gastric juice and a carbonated drink in vitro. J Oral Rehabil 2001;28:1045-7.

19. Grenby TH, Phillips A, Desai T, Mistry M. Laboratory studies of the dental properties of soft drinks. Br J Nutr 1989;62:451-64.

20. Yu H, Wegehaupt FJ, Wiegand A, Roos M, Attin T, Buchalla W, et al. Erosion and abrasion of tooth-colored restorative materials and human enamel. J Dent 2009;37:913-22.

21. Yap AU, Lye KW, Sau CW. Surface characteristics of tooth-colored restoratives polished utilizing different polishing systems. Oper Dent 1997;22:260-5.

22. Abu-Bakr N, Han L, Okamoto A, Iwaku M. Changes in the mechanical properties and surface texture of compomer immersed in various media. J Prosthet Dent 2000;84:444-52.

23. Attar N. The effect of finishing and polishing procedures on the surface roughness of composite resin materials. J Contemp Dent Pract 2007;8:27-35.

24. Bertrand MF, Leforestier E, Muller M, Lupi-Pégurier L, Bolla M. Effect of surface penetrating sealant on surface texture and microhardness of composite resins. J Biomed Mater Res 2000;53:658-63. 